\title{
Understanding talent attraction: The influence of financial rewards elements on perceived job attractiveness
}

\author{
Authors: \\ Anton Schlechter ${ }^{1}$ \\ Angel Hung ${ }^{1}$ \\ Mark Bussin ${ }^{2}$ \\ Affiliations: \\ ${ }^{1}$ School of Management \\ Studies, University of Cape \\ Town, South Africa \\ ${ }^{2}$ Department of Industrial \\ Psychology and People \\ Management, University of \\ Johannesburg, South Africa \\ Correspondence to: \\ Anton Schlechter \\ Email: \\ anton.schlechter@uct.ac.za \\ Postal address: \\ School of Management \\ Studies, Private Bag, \\ Rondebosch 7701 \\ Cape Town \\ Dates: \\ Received: 14 May 2014 \\ Accepted: 25 Aug. 2014 \\ Published: 27 Nov. 2014 \\ How to cite this article: \\ Schlechter, A., Hung, \\ A., \& Bussin, M. (2014). \\ Understanding talent \\ attraction: The influence \\ of financial rewards \\ elements on perceived \\ job attractiveness. SA \\ Journal of Human Resource \\ Management/SA Tydskrif vir \\ Menslikehulpbronbestuur, \\ 12(1), Art. \#647, 13 pages. \\ http://dx.doi.org/10.4102/ \\ sajhrm.v12i1.647

\section{Copyright:} \\ (C) 2014. The Authors. \\ Licensee: AOSIS \\ OpenJournals. This work \\ is licensed under the \\ Creative Commons \\ Attribution License.

Orientation: In order to attract knowledge workers and maintain a competitive advantage, it is necessary for organisations to understand how knowledge workers are attracted to different types and levels of financial rewards.

Research purpose: This research investigated a set of financial reward elements (remuneration, employee benefits and variable pay) to determine whether knowledge workers perceived them as attractive inducements when considering a job or position.

Motivation for the study: In South Africa there is a shortage of talent, largely due to high rates of emigration of scarce skills (human capital). Financial rewards or inducements are necessary to attract talent and it is essential to assess which of these rewards are most successful in this regard.

Method: A $2^{3}$ full-factorial experimental design (field experiment) was used. The three financial reward elements (remuneration, employee benefits and variable pay) were manipulated in a fictitious job advertisement (each at two levels). Eight $(2 \times 2 \times 2=8$ ) different versions of a job advertisement were used as a stimulus to determine the effect of financial reward elements on perceived job attractiveness. A questionnaire was used to measure how participants perceived the attractiveness of the job. A convenience sampling approach was used. Different organisations throughout South Africa, as well as corporate members of the South African Reward Association, were asked to participate in the study. Respondents ( $n$ $=169$ ) were randomly assigned to the various experimental conditions (i.e. one of the eight advertisements). Data were analysed using descriptive statistics. A full-factorial analysis of variance was used to investigate if significant main effects could be found.

Main findings: Participants considered high levels of remuneration, the inclusion of benefits and variable pay to be significant job attraction factors within a reward package. Remuneration was found to have the largest main effect on job attractiveness of the three. Gender, race and age did not have statistically significant main effects on job attractiveness.

Practical/managerial implications: High levels of remuneration, benefits and variable pay should be incorporated and emphasised in organisational talent attraction strategies as they are attractive for knowledge workers. If organisations want to attract prospective talent they need to offer high levels of remuneration to make their offers appealing and attractive. Variable pay and benefits are, further, not sufficient to mitigate a low remuneration offer.

Contribution: This study adds to the body of social science research as few studies have empirically demonstrated a causal link between financial reward elements and job attractiveness within a controlled laboratory environment. There is also limited empirical research in South Africa that highlights the level and combinations of financial reward elements that are attractive for talented knowledge employees.

\section{Introduction}

\section{Problem statement}

\section{Key focus}

A critical component of talent management is reward management. Organisations must consider which rewards (monetary or non-monetary) are valued by employees and determine whether their configuration of total rewards will achieve the desired attraction and retention effects (Rumpel \& Medcof, 2006). This is especially true for attracting and retaining knowledge workers. Knowledge workers are considered to be critical to long-term organisational success and integral to an organisations' intellectual capital (Birt, Wallis, \& Winternitz, 2004).

Financial rewards such as remuneration have traditionally been a defining feature of the employment relationship. In order to attract much-needed knowledge workers and maintain a competitive advantage, it is necessary for organisations to understand whether knowledge 
workers are attracted to different types and levels of financial rewards.

\section{Background}

Human capital has become an important strategic resource for competitive advantage as differentiation now rests with the unique talents of the people in an organisation (Aguinis, Gottfredson \& Joo, 2012; Holland, Sheehan \& De Cieri, 2007). The war for talent is especially prevalent amongst knowledge workers as the economy has shifted from an industrial economy to a knowledge economy. According to Aguinis et al. (2012), there are few individuals within each industry who are considered top or scarce human capital. These individuals are often known as knowledge workers. One of the most important activities for organisations is thus the attraction of knowledge workers with scare skills (Aguinis et al., 2012; Holcombe-Ehrhart \& Ziegert, 2005; Tarique \& Schuler, 2010).

According to the African Association for Public Administration and Management (AAPAM), talent scarcity in Africa is a result of talented individuals migrating to developed countries. Primary reasons for the exodus of skills include poor remuneration, uncompetitive work environments and high levels of crime (AAPAM, 2008). Another reason is that many organisations in developed countries have attractive employer brands and they also offer benefits such as opportunities to become permanent residents or assisting with acquiring citizenship. The positive organisational image and benefits serve as effective attraction tools for hiring talent globally (Elegbe, 2010).

Knowledge workers are highly mobile and recognise that their skills are highly sought-after resources. Consequently, a highly mobile workforce and increasingly competitive labour market have highlighted the need to focus on talent management (Aiman-Smith, Bauer \& Cable 2001; D'Annunzio-Green, 2008; Tornikoski, 2011).

\section{Research purpose}

The five elements of total rewards can be categorised into financial and non-financial rewards (Armstrong \& Murlis, 2004). Financial rewards include remuneration, benefits, performance and recognition and non-financial rewards consist of work-life balance, development and career opportunities, as well as an array of other non-financial benefits that organisations offer employees. The experiment consisted of two levels of remuneration (low remuneration vs high remuneration), two levels of financial benefits (the presence of benefits vs no benefits) and two levels of variable pay (the presence of variable pay vs no variable pay). The overall purpose of this research was to show a causal link between financial reward elements and the perceived attractiveness of a job for prospective knowledge workers.

\section{Trends from research literature}

Pregnolato (2010) applied a choice-based conjoint analysis in South Africa that required participants to make (psychological) trade-offs in order to identify the ideal mix of reward elements and desired amount of total reward factors that would retain knowledge workers and, more specifically, employees from different race, gender and age groups ( $n=361$ knowledge workers from a broad spectrum of corporate organisations in South Africa).

Pregnolato (2010) found that of the financial and nonfinancial reward elements, financial rewards (i.e. monetary benefits, monetary recognition and remuneration) were the most important types of rewards to retain employees from various demographic groups. The current study builds on Pregnolato's study by focusing on the talent attraction aspect of talent management and using an experiment to investigate the causal relationship between these constructs.

Financial elements have traditionally been a defining feature of an employment relationship and research has found them to be one of the strongest attraction and retention measures (Tornikoski, 2011). However, with changing demographics as well as changes in the nature of the workplace (i.e. globalisation, diversification and telecommuting), non-financial reward elements such as workplace flexibility and opportunities for personal development have become increasingly important (Bussin, 2003). For example, Kearney (2003) has suggested that some employees are willing to forfeit high wages for nonfinancial rewards such as workplace flexibility. Therefore, by focusing only on the financial elements, one can determine whether financial reward elements alone are still relevant and important attributes to attract employees.

\section{Objectives}

The primary research objective of this study was to control for the various factors that influence job attraction by using an experiment to determine whether financial reward elements are important to knowledge workers, and to show that the presence and level of these rewards are important when attracting knowledge workers.

The following research question was derived:

- Do the type, levels and presence of financial reward elements influence employees' perception of the attractiveness of a job?

The following proposition was derived from the research question:

- Proposition 1: Financial reward elements (remuneration, benefits and variable pay) have an effect on job attractiveness.

\section{Contribution to field}

This study adds to the body of remuneration knowledge. There are limited empirical studies that have used social science research to demonstrate a causal link in the attractiveness of financial reward elements within a controlled or manipulated environment; this study builds on research from Pregnolato (2010). Furthermore, there is limited empirical research in South Africa that highlights 
the level and combinations of financial reward elements that are attractive for talented knowledge employees (Nieuwenhuizen, 2009).

The use of full-factorial experiments is limited within the domain of industrial and organisational psychology research. Therefore, another contribution lies in the method that was used to determine whether various financial reward elements are causally linked to job attractiveness for knowledge workers. Using an experimental approach adds to the body of social science research as limited studies have identified the attractiveness of financial reward elements in a controlled environment, and none have identified causal relationships between financial rewards and the level of perceived attractiveness of a job position (Nieuwenhuizen, 2009; Pregnolato, 2010).

\section{What will follow}

A review of the literature focusing on the role of financial reward elements in explaining job attractiveness is investigated next. A comprehensive description of the research methodology is then presented, followed by the results and a discussion thereof in the next sections.

\section{Literature review \\ Remuneration}

Remuneration is cash payments provided from an employer to an employee in exchange for the services rendered. The most common form of remuneration is a salary or fixed pay and the amount is usually determined by the organisation's pay structure (WorldatWork, 2011).

Mitchell and Mickel (1999) further propose that money consists of three components, namely affective, symbolic and behavioural components. The affective component suggests that on one end of a continuum there are some people who view money as important and valuable, whilst on the other end some people perceive the value of money as bad and evil. Symbolically, money is associated with attributes that most people strive for. These include achievement and recognition, status and respect, freedom and control and power. Money is often used to recognise accomplishments; it can provide the luxury of time and autonomy as well as power and access to resources (Mitchell \& Mickel, 1999). The behavioural component focuses on people's actions such as investing money (Mitchell \& Mickel, 1999).

Lievens, Decaesteker, Coetsier and Geirnaert (2001) suggest that remuneration policies are malleable and organisations can distinguish themselves from competitors by offering different levels of remuneration.

The symbolic component of money is particularly important for attraction purposes as the level of pay is an important organisational characteristic that influences people's initial assessment of job attractiveness (Lievens et al., 2001). The level of pay also acts as a vehicle for satisfying human needs such as status, achievement and recognition (Barber \& Bretz, 2000). In addition, Cable and Judge (1994) suggest that pay level has a direct effect on employee attraction because it determines the level of purchasing power. The higher the level of pay, the greater the purchasing power.

An organisation's remuneration system may influence the attractiveness of a job because remuneration systems can act as signalling devices that convey information about an organisation's values, culture, philosophy and practices (Rynes, 1987). Previous studies have also found remuneration to be one of the most important job attributes that applicants consider when looking for a job (Boswell, Roehling, LePine \& Moynihan, 2003; Jurgensen, 1978; Tornikoski, 2011; Van Rooy, 2010). Therefore, it is accepted that individuals are more attracted to organisations that offer higher levels of pay.

\section{Employee benefits}

WorldatWork (2011, p. 5) defines benefits as 'programs an employer uses to supplement the cash compensation that employees receive'. Armstrong and Murlis (2004) suggest that benefits provide a quantifiable value for employees and they may be deferred or contingent, like pension schemes, health and welfare plans and sick pay, or they may be immediate benefits such as company cars (Armstrong \& Murlis, 2004). Employee benefits serve as an attraction tool as they provide for the actual or perceived personal needs of employees such as security and in some cases they also provide assets (e.g. company cars) in addition to pay (Armstrong \& Murlis, 2004). Employees view the benefits they receive as the extent to which their organisations value their contributions and care about their well-being (Jensen, McMullen \& Stark, 2007; Rousseau \& Ho, 2000). An employee attraction and retention survey by WorldatWork (2007) found that 95\% of the participants rated medical plans as having a moderate to high impact on employee attraction. Similarly, more than $90 \%$ of the participants indicated that paid vacation has a moderate to high impact on employee attraction and retention. According to Dulebohn, Molloy, Pichler and Murray (2009), the renewed interest amongst applicants and employees in benefit packages can be attributed to trends such as the increasing number of women in the labour force and rising costs of benefits such as medical cover. Andrew (2012) notes that South Africans are paying up to five times more on health care than other nations.

\section{Performance and financial recognition}

Most managers and employees perceive the performance appraisal process as a means to obtain a salary increase or cash bonuses as a reward for their performance (Elegbe, 2010). According to Elegbe (2010), this perception is so strong that the performance appraisal processes has become meaningless if it is not linked to pay or rewards. Grigoriadis and Bussin (2007) suggest that it has become more difficult 
for organisations to differentiate between high-performing and low-performing employees based on their salaries alone. Furthermore, Miceli and Heneman (2000) suggest that organisations hiring from competitive labour markets are required to offer higher cash incentives in order to attract the best candidates. As a result, many organisations have adopted variable pay schemes, which are aimed at atracting talented individuals, differentiating employees and giving greater monetary recognition to high-performing employees (Armstrong \& Murlis, 2004; Grigoriadis \& Bussin, 2007; Jensen et al., 2007). Organisations that offer variable pay are more attractive to people who are performance or reward driven and value monetary recognition.

Sutherland and Jordaan (2004) suggest that knowledge workers value independence and individualism; therefore, personal achievement and recognition is an important motivator at work.

\section{Method}

\section{Research approach}

This study followed a quantitative research approach and a $2^{3}$ full-factorial experimental design (field experiment) was used to investigate the effect of financial reward elements on employees' perceptions of job attractiveness. The experiment consisted of two levels of remuneration (low remuneration vs high remuneration), two levels of financial benefits (the presence of benefits vs no benefits) and two levels of variable pay (the presence of variable pay vs no variable pay). The dependent variable was job attractiveness.

\section{Measures}

\section{Participants}

A convenience sampling approach was used for this study in order to maximise responses within the logistical and financial constraints. The questionnaire was distributed to companies in Cape Town and Johannesburg, as well as employees who are members of the South African Rewards Association (SARA). Two hundred and twenty questionnaires were distributed and 205 questionnaires were returned. Thirty-six participants were excluded from the analysis as their responses contained more than 20\% missing data. Consequently, the data from 169 completed questionnaires were analysed. This equates to a $76 \%$ response rate, which is considered to be high given that online surveys typically have a response rate of $7 \%$ (Bhattacherjee, 2012). The response group consisted of different age, gender, race and job level groups.

\section{Measuring instruments}

The questionnaire was self-reported, consisted of two subscales, job attraction and total rewards, and contained 32 closed-ended items in total. The mean time to complete the full questionnaire was approximately 10 minutes.

Job attraction: A five-item organisational attraction scale by Highhouse, Lievens and Sinar (2003) was adapted to measure job attraction. Highhouse et al. reported satisfactory reliability for this measure (Cronbach's alpha $=0.88)$. In addition, the scale consisted of relatively few items (i.e. five items). According to DeVellis (2003), shorter scales place less of a burden on respondents. The scale was adapted by replacing the word 'company' in the original scale with the word 'job'. A sample item of the original organisational attraction scale is 'I am interested in learning more about this company'. This item was adapted to 'I am interested in learning more about this job'. Participants were asked to respond to the five items using a five-point Likert-type scale ( 1 = strongly disagree; 5 = strongly agree).

Total rewards: Participants were asked to complete a total rewards questionnaire, which was developed using the WorldatWork total rewards model (Pregnolato, 2010). The aim of this item set was to determine which total reward elements were considered most attractive. The scale consisted of 20 items which covered the five dimensions of the total rewards model, namely: (1) performance and recognition, (2) work-life balance, (3) learning, (4) career advancement and (5) remuneration and benefits (Pregnolato, 2010). The dimensions of total rewards had moderate Cronbach's alpha values that ranged from 0.51 to 0.71 , based on the previous study (Pregnolato, 2010). Participants were asked to respond using a five-point Likert-type scale where 1 represented 'Not at all important' and 5 'Very important'.

Demographics and career information: A demographics and career information section was included at the end of the questionnaire. Demographic information included age, gender, race and country of origin. Career information included length of employment in current organisation, job position and industry.

Manipulation check: A manipulation check was conducted to determine whether the financial reward manipulations produced the intended effect in the kind of respondents that would participate in the study. The manipulation check consisted of qualitative and quantitative questions. The aim was to verify the difference between the various manipulations. A sample question for remuneration was 'What do you think would be a high and low salary?' This included a follow-up question such as 'Do you consider earning below the 50th percentile of the market to be a high or low salary?' A sample question for benefits and variable pay was 'What do you consider benefits (or variable pay) to consist of when given as a reward package?' The qualitative questions were followed by a request to rate the level of attractiveness of the six manipulated financial rewards on a five-point Likert-type scale $(1=$ very unattractive; 5 = very attractive).

\section{Design}

Eight job advertisements for a fictitious position were designed $\left(2^{3}\right.$ or $\left.2 \times 2 \times 2=8\right)$. The different levels and 
combinations of financial reward elements were manipulated according to the design matrix illustrated in Table 1.

For remuneration, +1 represents remuneration that is above the 75 th percentile of the market whilst -1 represents remuneration that is at or below the 50th percentile of the market. For benefits, +1 indicates that benefits are present (offered), which Pregnolato (2010) classifies as employer contributes $100 \%$ of total retirement fund contribution plus highest level of medical cover, whilst -1 indicates that there are no benefits. For variable pay, +1 indicates that variable pay is present (offered), which is represented by a 13th cheque as well as a performance bonus and share options (Pregnolato, 2010), whilst -1 indicates that there is no variable pay.

Eight different versions of the job advertisement were used as stimuli to determine the effect of financial rewards on perceived job attractiveness. Advertisements were chosen to improve external validity as they represent real-life situations. These advertisements were also designed so as not to include any additional information that could influence their attractiveness for some respondents (for example, a brand or reference to other aspects of the employee value proposition on offer).

Before distributing the advertisements, a manipulation check was conducted to determine whether participants understood the job advertisements in the way that was intended (e.g. low remuneration vs high remuneration as discussed above).

The software programme Qualtrics was used to randomly assign participants to each experimental group and to so ensure that the groups were homogenous and therefore comparable. Random assignment of participants to the eight different conditions (advertisements) meant an even distribution. The groups were found not to be significantly different on any demographic variable, and were therefore considered to be similar and comparable.

Eight versions of an advertisement for a job position were developed and these were randomly presented to participants when they accessed the survey (random assignment to a condition) using Qualtrics. Each participant received one advertisement followed by a questionnaire to assess their perception of the level of attractiveness of the advertised position. Thereafter participants were asked to complete a second questionnaire (total rewards questionnaire).

\section{Analysis}

As part of the manipulation check described above (i.e. prior to administration of the full research questionnaire), a paired sample $t$-test $(n=12)$ was conducted to determine if the manipulated financial reward elements produced significantly different job attractiveness scores. This was in fact the case for all three manipulations of the reward elements.

Descriptive analysis was used to assess the nature of the data whilst a full-factorial analysis of variance (ANOVA) was used to assess the effect of the financial reward elements on perceived job attractiveness. All statistical analyses, including reliability analysis, factor analysis and ANOVA, were performed using SPSS for Windows, version 21.

\section{Validity}

Principal component analysis (PCA) was used to test the unidimensionality of the job attraction scale. The KaiserMeyer-Olkin (KMO) measure of sampling adequacy and Bartlett's test of sphericity were conducted to determine whether it was appropriate to proceed with PCA. According to Burns and Burns (2008), the KMO measure should be greater than 0.5 and Bartlett's test should be significant in order for factor analysis to be appropriate. A significant Bartlett's test shows that there is some degree of correlation between the variables (Burns \& Burns, 2008).

\section{Results \\ Demographic characteristics of the sample}

The demographic characteristics of the sample are depicted in Table 2.

The ages of the respondents $(n=169)$ ranged from 22 to 66 years $(\mathrm{M}=35.4 ; \mathrm{SD}=10.3)$. The average number of years of employment was 7.2 years $(\mathrm{SD}=5.5)$. The range of number of years of employment was 6 months to more than 20 years.

Table 2 indicates a predominately white sample (56\%). It is likely that these participants are reflective of the current racial profile of knowledge workers in South Africa.

According to Pregnolato (2010), knowledge workers operate at different levels in an organisation. Table 2 indicates that

TABLE 1: A $2^{3}$ design showing the eight experimental groups and the mean score for perceived job attractiveness achieved for each.

\begin{tabular}{|c|c|c|c|c|c|}
\hline Conditions & $X_{1}:$ Remuneration & $X_{2}:$ Benefits & $X_{3}$ : Variable pay & Mean: Job attractiveness & $n$ \\
\hline 1 & +1 & +1 & +1 & 3.91 & 21 \\
\hline 2 & +1 & +1 & -1 & 3.62 & 19 \\
\hline 3 & +1 & -1 & -1 & 3.40 & 22 \\
\hline 4 & -1 & -1 & -1 & 1.63 & 22 \\
\hline 5 & -1 & -1 & +1 & 2.37 & 20 \\
\hline 6 & -1 & +1 & +1 & 2.72 & 22 \\
\hline 7 & -1 & +1 & -1 & 2.60 & 20 \\
\hline 8 & +1 & -1 & +1 & 3.48 & 23 \\
\hline
\end{tabular}


TABLE 2: Demographic characteristics of the sample.

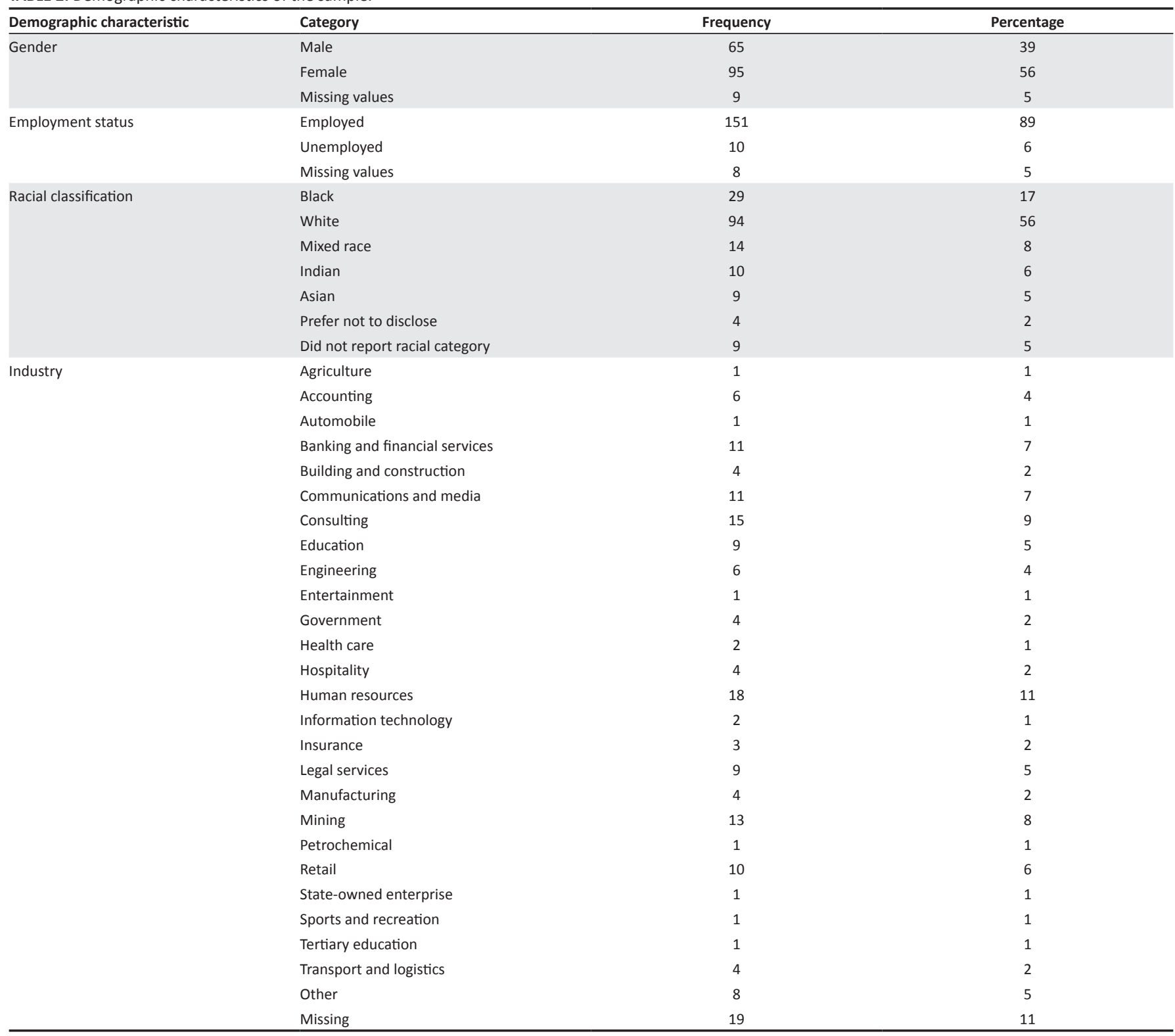

$N=169$.

most of the employed participants are in non-managerial roles, with participants in middle management and senior management having nearly equal representation. Respondents were drawn from a wide range of industries. The largest response group was from human resources, followed by consulting, mining, banking and financial services and communications and media respectively.

\section{Assessing unidimensionality of the job attraction scale Validity}

The KMO measure of sampling adequacy was 0.89 and Bartlett's test was significant $(\chi 210=754 ; p<0.001)$. It was therefore deemed appropriate to proceed with PCA. In terms of selecting the meaningful factors, Burns and Burns (2008) suggest Kaiser's rule, which is to select components with eigenvalues greater than 1 as they explain more variance than an individual item in the data set. The PCA revealed that there was only one factor with an eigenvalue greater than 1 (eigenvalue $=3.98$ ) for the job attractiveness scale and it accounted for $79.7 \%$ of the variance. The scree plot, using Catell's scree test, also suggested that there was only one factor as the curve begins to flatten between factors 2 and 3 . With regard to the component matrix, factor loadings of less than 0.30 are considered insignificant and are suppressed (Burns \& Burns, 2008).

All five items of the job attraction scale loaded significantly on one component (factor loadings $=0.81<r<0.93$ ), which was labelled job attractiveness. Based on this basket of evidence the scale could be considered unidimensional and the factor it was assumed to measure was the attractiveness of the job.

\section{Reliability}

The internal consistency of the job attraction scale was assessed using Cronbach's alpha. The scale consisted of five 
items and showed satisfactory reliability (Cronbach's $\alpha=$ 0.93). With regard to the corrected item-total correlations, Burns and Burns (2008) suggest that the rule of thumb is to delete any items with a corrected item-total correlation of less than 0.30 . In this case, no items were deleted as all five items had item-total correlations greater than 0.30 (corrected itemtotal correlations $=0.72<r<0.89$ ). The job attraction scale was thus also considered to be reliable.

\section{Assessing the total rewards scale Validity}

PCA was used to determine the underlying factor structure of the total rewards scale. Pregnolato (2010) suggests that the factors that make up the total rewards scale are independent. Therefore, PCA using varimax with Kaiser normalisation rotation was selected as varimax is an orthogonal rotation strategy that treats factors as being independent and maintains the uncorrelated nature of the factors with one another (Burns \& Burns, 2008). In addition, varimax increases the interpretability by rotating factors to ensure that there is more discrimination between high and low loading variables (Burns \& Burns, 2008).

The KMO and Bartlett's test of sphericity showed that it was appropriate to proceed with PCA $(\mathrm{KMO}=0.77 ; \chi 2190=991$; $p<0.001)$. The scree plot, using Catell's scree test, confirmed the presence of four factors (Burns \& Burns, 2008). Seven items were removed after the first round of PCA as there was evidence of cross-loading (i.e. a difference in factor loadings of $>0.25$ on two factors). A repeated PCA showed evidence of cross-loading for an additional two items. The third round of PCA showed cross-loading for one item and this item was deleted. The fourth round of PCA was accepted as the final factor structure as the remaining ten items had factor loadings above 0.30 and there was no evidence of crossloading. Table 3 illustrates the items within the total rewards scale that loaded onto four factors and explained $67.27 \%$ of the total variance. Three items loaded significantly on factor 1 (eigenvalue $=2.83$; explained variance $=28.3 \%$ ), three items loaded on factor 2 (eigenvalue $=1.51$; explained variance $=$ $15.1 \%$ ), two items loaded significantly on factor 3 (eigenvalue $=1.29$; explained variance $=12.9 \%$ ) and two items loaded on factor 4 (eigenvalue $=1.10$; explained variance $=10.9 \%$ ).

The factors were labelled Remuneration and Benefits, Learning and Career Advancement, Work-Life Balance (Practices) and Work-Life Balance (Organisational Climate) respectively. It should be noted that items that originally were meant to measure Work-Life Balance were divided into two separate sets of items. One set of items (factor 3) reflected the underlying constructs of work-life balance practices such as a balanced lifestyle and flexible work arrangements, whereas factor 4 reflected work-life balance factors such as social friendships at work, which contribute to the organisational climate.

\section{Reliability}

The SPSS item-analysis technique was used to assess the internal consistency of the total rewards scale. Reliability analysis was conducted on the PCA-derived measurement model. The PCA-derived total reward scale comprised of four factors. The Remuneration and Benefits factor consisted of three items and it showed a Cronbach's alpha of 0.74 , which indicated satisfactory reliability. No items were removed as the corrected item-total correlations were all acceptable $(r>0.30)$. The Learning and Career Advancement factor consisted of three items and it showed a moderate reliability (Cronbach's $\alpha=0.62$ ). The corrected item-total correlations were above 0.30 ; therefore, no items were removed. The Work-Life Balance (Practices) factor included two items and it showed a moderate reliability (Cronbach's $\alpha=0.61$ ). No items were removed as the corrected item-total correlations were all above 0.30. Lastly, the Work-Life Balance (Organisational Climate) factor consisted of two items and showed a Cronbach's alpha of 0.61 , which indicated a moderate reliability. No items were removed as the corrected item-total correlations of the items were acceptable.

\section{Descriptive statistics Job attractiveness}

Job attractiveness was measured on a five-point Likert-type scale with 5 being the highest score, 3 being the midpoint and 1 being the lowest score.

\section{Financial reward elements and job attractiveness}

Remuneration that is above the 75th percentile of the market had the highest mean attractiveness score (Mean $=3.59$, SD $=0.7$ ), followed by benefits present and variable pay present (Mean =3.21, $\mathrm{SD}=1.00 ;$ Mean $=3.14, \mathrm{SD}=0.99$, respectively). Participants perceived high remuneration (above the 75th percentile of the market) to be more attractive than low remuneration (at or below the 50th percentile of the market) and having benefits and variable pay present as a reward package was more attractive than no benefits or variable pay. A summary of the descriptive statistics are presented in Table 4.

There was more variability in attractiveness scores for remuneration that is at or below the 50th percentile of the market. The response for lower levels of remuneration was also positively skewed, which suggested that the majority of the participants had low attractiveness scores for remuneration that is at or below the 50th percentile of the market. In contrast, there was less variability on attractiveness scores for remuneration that is above the 75 th percentile of the market, as scores were clustered at the high end of the scale. These results are illustrated in Figure 1.

Compared to having no benefits, the distribution for benefits present was slightly skewed to the left (negatively skewed). This suggested that the higher frequencies are concentrated towards the high scores and that having benefits was more attractive than no benefits. These results are illustrated in Figure 2. 
TABLE 3: Factor analysis for the total rewards scale.

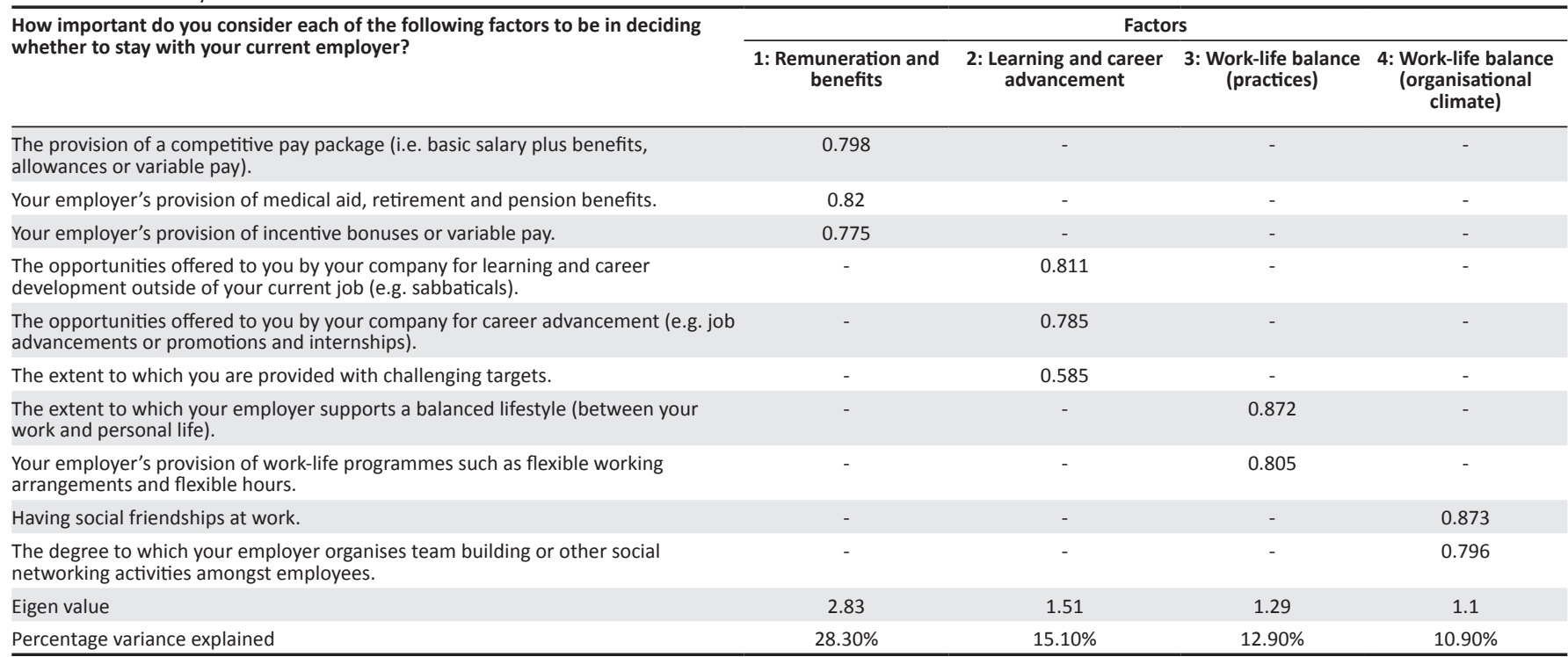

Extraction method: Principal component analysis.

Rotation method: Varimax with Kaiser normalisation.

TABLE 4: Descriptive statistics of the manipulated financial reward elements.

\begin{tabular}{|c|c|c|c|c|c|c|}
\hline Reward & Elements & $N$ & Minimum & Maximum & Mean & Standard deviation \\
\hline \multirow[t]{2}{*}{ Remuneration } & Above the 75 th percentile of the market & 86 & 1 & 5 & 3.59 & 0.7 \\
\hline & At or below the 50th percentile of the market & 83 & 1 & 5 & 2.32 & 0.97 \\
\hline \multirow[t]{2}{*}{ Benefits } & Present & 80 & 1 & 5 & 3.21 & 1 \\
\hline & Not present & 89 & 1 & 5 & 2.75 & 1.07 \\
\hline \multirow[t]{2}{*}{ Variable pay } & Present & 88 & 1 & 5 & 3.14 & 0.99 \\
\hline & Not present & 81 & 1 & 5 & 2.78 & 1.1 \\
\hline
\end{tabular}

$n=169$.

Having variable pay had a slightly higher mean than no variable pay. In addition, compared to no variable pay, the scores for variable pay present were relatively clustered towards the high end of the scale which suggested that having variable pay was more attractive than no variable pay. These results are illustrated in Figure 3.

Figure 4 shows that a reward package consisting of remuneration that is above the 75th percentile of the market and having benefits present was more attractive than a reward package comprising of remuneration above the 75th percentile of the market but without benefits.

Similarly, a reward package consisting of remuneration that is above the 75th percentile of the market with variable pay was more attractive than having remuneration above the 75th percentile of the market with no variable pay. Remuneration at or below the 50th percentile of the market with no variable pay was the least attractive compared to remuneration at or below the 50th percentile with variable pay present. This is illustrated in Figure 5.

In terms of benefits and variable pay, Figure 6 below shows that having both of them as a reward package was more attractive than having benefits only. It is worth noting that having only benefits as a reward was equally attractive as having variable pay only.

\section{Total rewards and job attractiveness}

Mean attractiveness scores for each of the four total reward dimensions are presented in Table 5. Remuneration and Benefits were rated as the most important total rewards in attraction, followed closely by Work-Life Balance (Practices) and Learning and Career Advancement. Work-Life Balance (Organisational Climate) had the lowest rating in terms of its overall importance in attraction. It should be noted that the means, at least for three of the four, were very similar to one another.

\section{Analysis of variance}

A full-factorial ANOVA was used to determine the effect of financial reward elements on job attractiveness. This technique was used as it examines the individual and joint effect of the independent variables (remuneration, benefits and variable pay) on one dependent variable (job attractiveness). Bhattacherjee (2012) and Simmons, Nelson and Simonsohn (2011) suggest that each experimental condition or group should have least 20 participants in order to conduct a factorial ANOVA.

In this case, experiment group 2, which consisted of remuneration above the 75th percentile of the market, benefits present and no variable pay, had 19 participants. Burns and Burns (2008) suggest that an ANOVA is a relatively robust technique and having 19 participants 


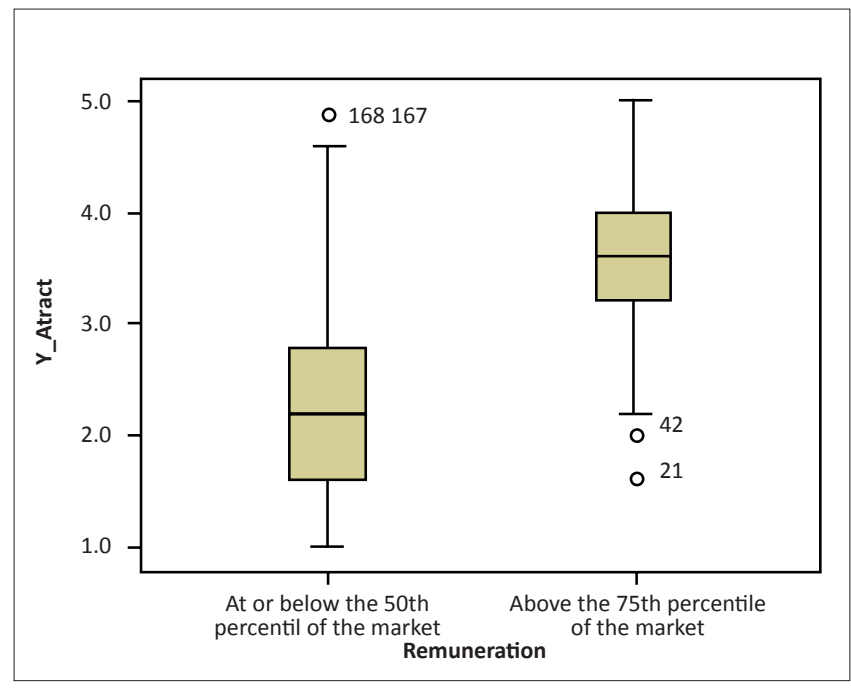

Source: Authors' own creation

FIGURE 1: Comparison of the means for perceived job attractiveness based on two levels of remuneration.

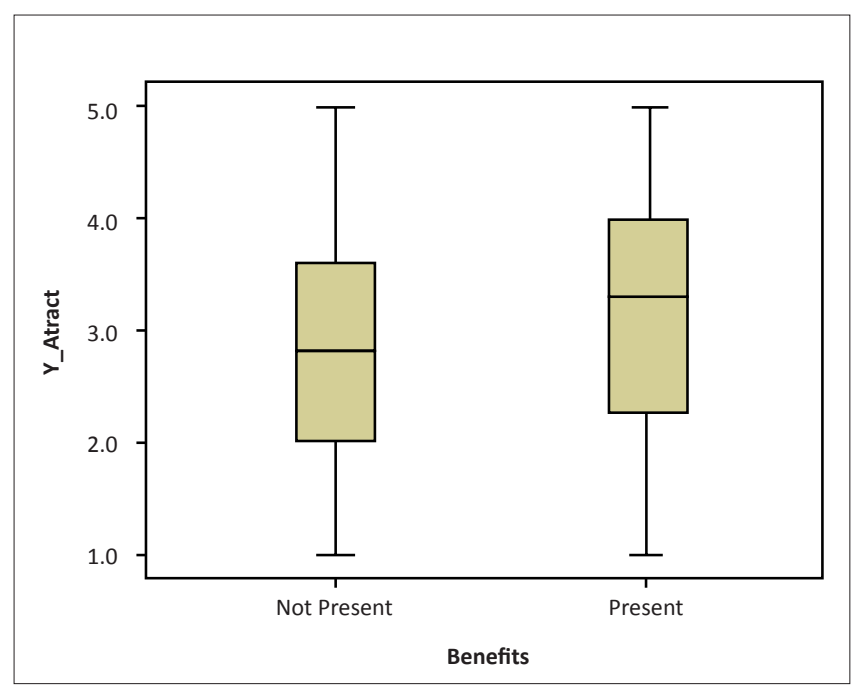

Source: Authors' own creation

FIGURE 2: Comparison of the means for perceived job attractiveness based on two levels of benefits.

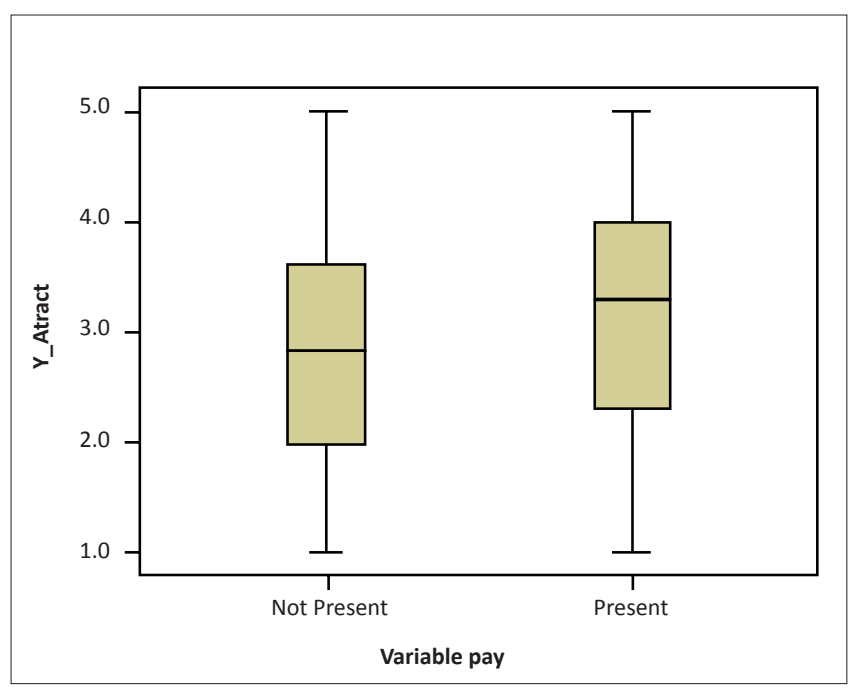

Source: Authors' own creation

FIGURE 3: Comparison of the means for perceived job attractiveness based on two levels of variable pay.

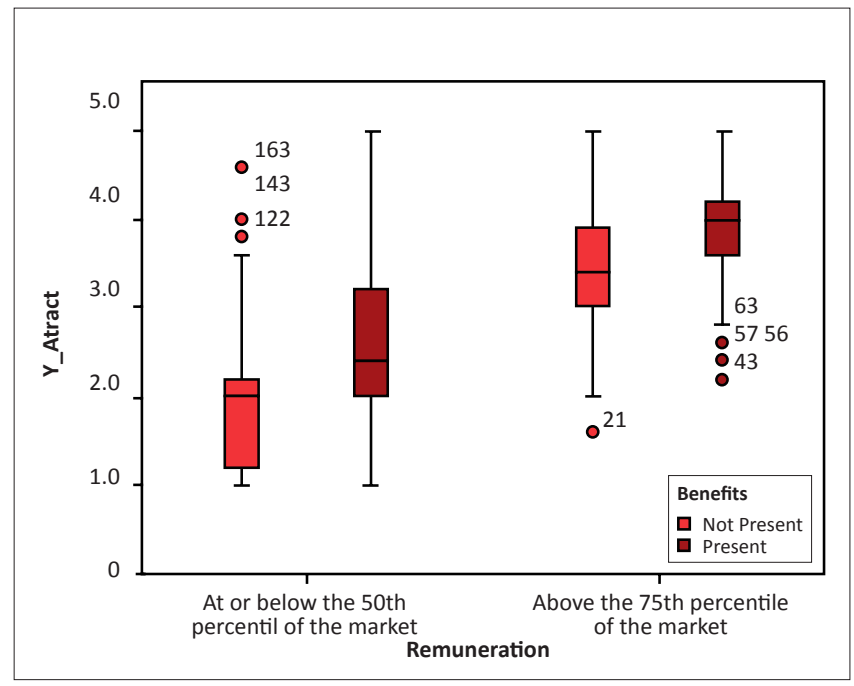

Source: Authors' own creation

FIGURE 4: Box plot of a reward package consisting of remuneration and benefits.

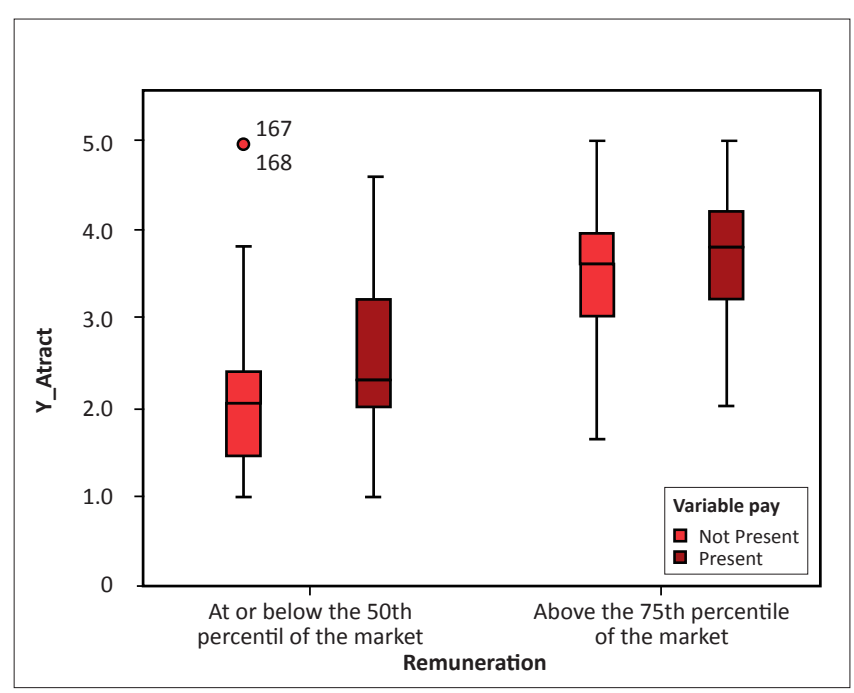

Source: Authors' own creation

FIGURE 5: Box plot of a reward package consisting of remuneration and variable pay.

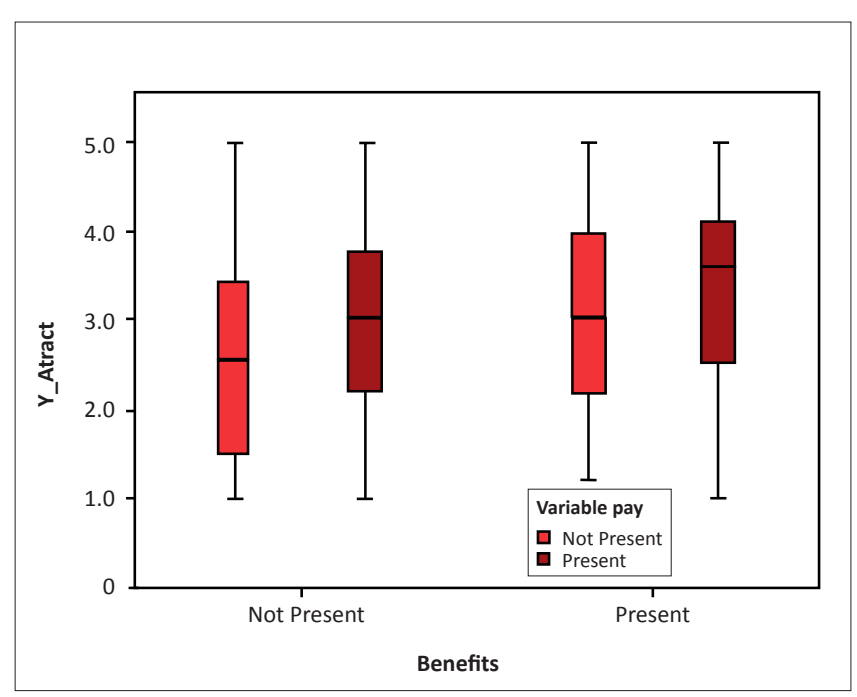

Source: Authors' own creation

FIGURE 6: Box plot of a reward package consisting of benefits and variable pay. 
TABLE 5: Descriptive statistics of the total reward elements.

\begin{tabular}{|c|c|c|c|c|c|}
\hline Reward & $N$ & Minimum & Maximum & Mean & Standard deviation \\
\hline Remuneration and benefits & 161 & 2.67 & 5 & 4.36 & 0.54 \\
\hline Learning and career Advancement & 161 & 2 & 5 & 4.21 & 0.57 \\
\hline Work-life balance (practices) & 161 & 2 & 5 & 4.32 & 0.63 \\
\hline Work-life balance (organisational climate) & 161 & 1 & 5 & 3.39 & 0.84 \\
\hline
\end{tabular}
$n=161$.

is sufficiently close to 20 participants; therefore, it was deemed appropriate to use an ANOVA. According to Burns and Burns (2008), statistical tests such as an ANOVA should only be used when normality (or close approximations to it) can be assumed. Therefore, tests for normality (Kolmogorov-Smirnov and Shapiro-Wilk tests) and homogeneity of variance (Levene's tests) were performed in each of the cases to determine whether it was appropriate to proceed with the ANOVA analysis. The sizes of the groups are reflected in Table 1.

The mean attractiveness scores for each condition are also summarised in Table 1. It should be noted that the highest mean attractiveness scores were achieved for the four conditions where high pay $(>75$ th percentile) was present and were lowest when low pay $(<50$ th percentile $)$ was present. A reward package consisting of remuneration that is above the 75th percentile of the market and having benefits present $(M=3.62)$ was more attractive than a reward package comprising of remuneration above the 75 th percentile of the market with variable pay present $(\mathrm{M}$ =3.48). A reward package consisting of remuneration that is at or below the 50th percentile of the market without any benefits or variable pay was perceived as the least attractive reward package $(\mathrm{M}=1.63)$, whilst the highest mean score was achieved when presenting remuneration that is at or above the 75th percentile and having benefits and having variable pay $(\mathrm{M}=3.91)$.

The normality (or close approximations to it) assumption for the financial reward elements (remuneration, benefits and variable pay) were satisfied. In cases where it was not satisfied, it was believed that an ANOVA was robust enough to deal with deviations from normality. Therefore, Levene's test of homogeneity was performed to determine whether the second assumption of an ANOVA was satisfied.

The Levene's test was not significant $\left(F_{7,161}=1.25 ; p=\right.$ 0.28 ), which showed that the homogeneity of variance assumption for the ANOVA was supported. It was thus appropriate to conduct a factorial ANOVA. The distribution of the residuals was also tested and there were no biases present in the data. In addition, the homogeneity of the groups was tested and they were found to be homogenous.

The results of the ANOVA are illustrated in Table 6 and revealed that there were significant main effects for remuneration $\left(F_{1}=109.56 ; p<0.001\right.$; partial $\left.\varepsilon^{2}=0.41\right)$, benefits $\left(F_{1}=16.46 ; p<0.001\right.$, partial $\left.\varepsilon^{2}=0.09\right)$ and variable pay $\left(F_{1}=6.40 ; p<0.001 ;\right.$ partial $\left.\varepsilon^{2}=0.04\right)$. In addition, the eta-squared effect sizes and observed power showed that remuneration had the strongest main effect. Burns and Burns (2008) suggest that measures of effect size complement tests of statistical significance as they provide information about the amount of impact an independent variable has on the observed effect (dependent variable). Therefore, measures of effect size can be used to rank several independent variables within an experiment as an indication of the relative importance of each variable. As mentioned above, remuneration had the strongest impact on job attractiveness followed by benefits and variable pay respectively. This result supported the hypothesis that financial reward elements (remuneration, benefits and variable pay) have an effect on job attractiveness. The results further suggested that remuneration was considered to be more important or attractive than benefits and variable pay.

Main effects were found for each of the financial reward elements; however, no significant interaction effects were found between remuneration, benefits and variable pay at the $95 \%$ confidence level. The three-way interaction effect (remuneration $\times$ benefits $\times$ variable pay) is significant when applying a $90 \%$ confidence level $(p=0.088$ or $p<$ 0.1 ), which, given the small sample size, can be justified. No significant two-way interaction effects were observed.

Gender, race and age had no significant main effects on job attractiveness.

\section{Discussion Outline of the results Total rewards}

The total rewards questionnaire identified which dimensions of the total rewards model are considered important to knowledge workers when deciding on a job position. The results of the total rewards questionnaire showed that the four dimensions of the total rewards model, namely (1) Remuneration and Benefits, (2) Work-Life Balance (practices), (3) Work-Life Balance (Organisational Climate) and (4) Learning and Career Advancement, were almost equally important to knowledge workers. Remuneration and Benefits achieved the highest mean attractiveness score, and Work-Life Balance (Organisational Climate) the lowest. This suggested that knowledge workers value remuneration and benefits the most and they are likely to respond favourably to any total reward mix offered by organisations. The problem with this approach, however, is that it does not discern between the reward elements. 
TABLE 6: Results of full-factorial analysis of variance showing the impact of financial rewards on job attraction.

\begin{tabular}{|c|c|c|c|c|c|c|c|c|}
\hline Source & Type III sum of squares & $d f$ & Mean square & $F$ & Significance & Partial eta-squared & Noncent. parameter & Observed power ${ }^{b}$ \\
\hline Corrected model & $87.812^{\mathrm{a}}$ & 7 & 12.55 & 20.19 & 0.000 & 0.47 & 141.30 & 1.00 \\
\hline Intercept & 1473.706 & 1 & 1473.71 & 2371.36 & 0.000 & 0.94 & 2371.36 & 1.00 \\
\hline Remuneration & 68.087 & 1 & 68.09 & 109.56 & 0.000 & 0.41 & 109.56 & 1.00 \\
\hline Benefits & 10.232 & 1 & 10.23 & 16.46 & 0.000 & 0.09 & 16.46 & 0.98 \\
\hline Variable pay & 3.978 & 1 & 3.98 & 6.40 & 0.012 & 0.04 & 6.40 & 0.71 \\
\hline Remuneration (Benefits) & 1.155 & 1 & 1.16 & 1.86 & 0.175 & 0.01 & 1.86 & 0.27 \\
\hline Benefits (Variable pay) & 0.445 & 1 & 0.45 & 0.72 & 0.399 & 0.00 & 0.72 & 0.13 \\
\hline $\begin{array}{l}\text { Remuneration (Benefits and } \\
\text { Variable pay) }\end{array}$ & 1.831 & 1 & 1.83 & 2.95 & 0.088 & 0.02 & 2.95 & 0.40 \\
\hline Error & 100.055 & 161 & 0.62 & - & - & - & - & - \\
\hline Total & 1676.64 & 169 & - & - & - & - & - & - \\
\hline Corrected total & 187.867 & 168 & - & - & - & - & - & - \\
\hline
\end{tabular}

$a, R$-squared $=0.467$ (Adjusted $R$-squared $=0.444$ ); ${ }^{\text {b }}$ Computed using alpha $=0.05$.

It offers each reward element separately and asks the question of attractiveness, resulting in a case of if offered, people would take all forms of reward at the highest level. This kind of outcome is less useful to organisations when optimising their reward strategies and offerings.

\section{Financial reward elements and job attractiveness}

The experiment showed that all three financial reward elements (remuneration, employee benefits and variable pay) significantly caused or influenced perceived attractiveness of a position, with remuneration being by far the most important or influential of the three. Furthermore, the three financial reward elements were found to interact with one another. This means that each financial reward had an independent effect on job attractiveness, but also that in combination they influence job attractiveness (but only when all three are present). A possible explanation is that each financial reward element contributes to economic and personal security in different ways. For example, remuneration and variable pay are used to obtain basic needs such as food and clothing whilst benefits are associated with security needs such as medical aid and insurance. Given the current economic situation in South Africa, where the state is recovering from an economic recession, it is likely that employees value tangible financial rewards in order to fulfil their basic security and economic needs.

This study expanded on previous research conducted by Pregnolato (2010) and it has made a number of contributions to the attraction and total rewards literature. Firstly, there is limited empirical social science research in South Africa that highlights a set of specific financial reward elements (remuneration, employee benefits and variable pay) that will attract talented employees. Few researchers have also focused on the financial reward elements only; researchers such as Van Rooy (2010) and Pregnolato (2010) focused on the financial as well as non-financial aspects of the total rewards model. The current study found that the financial reward elements deemed important for talent retention (Pregnolato, 2010) were also perceived as attractive inducements for talent attraction purposes. This suggests that financial rewards are important strategic resources that can be used in the area of talent management.

In addition, the use of full-factorial experiments is limited in the domain of organisational psychology. An additional contribution therefore lies in the method that was used to determine whether various financial reward elements are attractive to knowledge workers. Using an experimental approach adds to the body of social science research as no prior studies have identified the attractiveness of financial reward elements in a controlled environment, and causal relationships between financial rewards and the level of perceived attractiveness of a job position have also been explored. This links directly to Hertzberg, Mausner and Snyderman's (1957) theory, which divides job satisfaction into psychological factors and hygiene factors. It can be argued that if the hygiene factors are removed, it is unlikely that workers will be satisfied. Psychological factors constitute elements such as achievement and advancement whilst hygiene factors constitute elements such as organisational policies, quality of supervision, working conditions, salary, relationship with subordinates and peers, status and security. Employee engagement has its roots in the seminal work conducted on employee motivation in the form of intrinsic motivation (Hertzberg et al., 1957).

\section{Practical implications}

The findings of the current study make a practical contribution to organisations concerned with talent scarcity that are searching for effective methods to attract talented candidates. According to Elegbe (2010), what employers consider to be attractive inducements may not be attractive to potential employees. The findings of the current study provide organisations with an indication of employees' perceived level of attractiveness of the three financial reward elements. Organisations should consider the levels at which these financial rewards are offered when developing their attraction strategies, particularly in terms of the basic pay that is offered. In addition, organisations may now have greater insight into whether their current attraction strategies are aligned with the financial reward preferences of employees in general. 


\section{Limitations and recommendations}

Even though the experiment controlled for factors that influenced job attraction (such as employer branding and psychological contract), there were still extraneous variables that could not be controlled for. Therefore, a limitation of the study may be confounding variables such as the current economic environment and factors such as job stability. Financial rewards are usually more appealing during periods of economic instability as they satisfy basic needs such as food and security. Therefore, the results may be influenced by the effects of recovering from an economic recession. Another limitation may be the fact that elements that could be specifically attractive to knowledge workers such as flexibility were not specifically considered. It is likely that the results would differ if further research was to be conducted during a period of greater economic stability.

Another confounding variable could be the organisational climate. Since a non-random (convenience) sampling method was used, it was not possible to determine the economic status and climate of the organisations each participant belonged to. For example, some organisations may have been experiencing organisational restructuring such as retrenchment or a merger. These activities may influence factors such as job security which could have contributed to employees being more attracted to specific financial rewards during this period. Therefore, it is recommended that future research adopt a systematic random sampling method where organisational climate of the sample is known, as it could produce different responses.

\section{Conclusion}

Winning the war for talent is about the timeless principles of attracting, motivating and retaining talented employees. The current study focused on attracting talent and the aim was to determine whether financial reward elements, including remuneration, benefits and variable pay, are still important for attracting knowledge workers. Results showed that all three financial reward elements significantly influenced job attractiveness, with remuneration having the most impact on job attractiveness. In addition, having high remuneration (remuneration above the 75 th percentile of the market), benefits (employer contributes 100\% of total retirement fund contribution plus highest level of medical cover) and variable pay (13th cheque as well as a performance bonus and share options) was more attractive than having low remuneration (remuneration that is at or below the 50th percentile of the market) and benefits and variable pay. It is also interesting to note that being offered low remuneration and variable pay was less attractive than high remuneration and no variable pay.

If organisations are to attract the best talent, they are going to have to offer higher levels of pay. Variable pay and benefits add to the attractiveness of a job, but are not enough to stand on their own. One could argue that variable pay and benefits are a necessary but not sufficient condition for attractiveness. Also, when attracting talent it would be wise to emphasise the fact that the offer is of a higher level, if that is the case. The study further showed that gender, race and age had no effect on the perceived attractiveness of the financial reward elements.

\section{Acknowledgements}

The authors acknowledge Professor Charlene Gerber for her guidance and assistance with the research design of this study.

\section{Competing interests}

The authors declare that they have no financial or personal relationship(s) that may have inappropriately influenced them in writing this article.

\section{Authors' contributions}

A.S. (University of Cape Town) was the principle investigator, project leader and academic supervisor and was responsible for the design and execution of the project. A.H. (University of Cape Town) was responsible for fieldwork and writing up the research. Professor M.B. (University of Johannesburg) contributed to the preparation of the manuscript.

\section{References}

African Association for Public Administration and Management. (2008). Enhancing professionalization of human resource management in the public sector in Africa. Retrieved February 2013, from http://www.aapam-org/apsl.html

Aguinis, H., Gottfredson, R.K., \& Joo, H. (2012). Using performance management to win the talent war. Business Horizons, 55, 609-616. http://dx.doi.org/10.1016/j. bushor.2012.05.007

Aiman-Smith, L., Bauer, T.N., \& Cable, D.M. (2001). Are you attracted? Do you intend to pursue? A recruiting policy capturing study. Journal of Business and Psychology, 16(2), 219-237. http://dx.doi.org/10.1023/A:1011157116322

Andrew, M. (2012, 07 September). South Africa's healthcare declining. Mail and Guardian. Retrieved February 2013, from http://mg.co.za/article/2012-09-07motsoaledi-sahealth-care-declining

Armstrong, M., \& Murlis, H. (2004). Reward management: A handbook of remuneration strategy and practice. (5th ed.). London, England: Kogan Page Limited.

Barber, A.E., \& Bretz, R.D. (2000). Compensation, attraction and retention. In S.L. Rynes, \& B. Gerhart (Eds.), Compensation in organizations (pp. 273-310). San Francisco, CA: Jossey-Bass Publishers.

Bhattacherjee, A. (2012). Social science research: Principles, methods, and practices. USF Open Access Textbooks Collection. Retrieved February 2013, from http://scholarcommons.usf.edu/oa_textbooks/3

Birt, M., Wallis, T., \& Winternitz, G. (2004). Talent retention in a changing workplace: An investigation of variables considered important to South African talent. South African Journal of Business Management, 35(2), 25-31.

Boswell, W.R., Roehling, M.V., LePine, M.A., \& Moynihan, L.M. (2003). Individual job choice decisions and the impact of job attributes and recruitment practices: A longitudinal field study. Human Resource Management, 42(1), 23-37. http://dx.doi.org/10.1002/hrm.10062

Burns, R.B., \& Burns, R.A. (2008). Business research methods and statistics using SPSS. London, England: Sage Publications Ltd.

Bussin, M. (2003). Doctor of Commerce research report. Johannesburg, South Africa: Rand Afrikaans University.

Cable, D.M., \& Judge, T.A. (1994). Pay preferences and job search decisions: A person-organization fit perspective. Personnel Psychology, 47, 317-348. http://dx.doi.org/10.1111/j.1744-6570.1994.tb01727.x

D'Annunzio-Green, N. (2008). Managing the talent management pipeline: Towards a greater understanding of senior managers' perspectives in the hospitality and tourism sector. International Journal of Contemporary HospitalityManagement 20(7), 807-819. http://dx.doi.org/10.1108/09596110810897628

DeVellis, F.R. (2003). Scale development: Theory and applications. (2nd edn.) Thousand Oaks, CA: Sage Publications.

Dulebohn, J.H., Molloy, J.C., Pichler, S.M., \& Murray, B. (2009). Employee benefits: Literature review and emerging issues. Human Resource Management Review, 19, 86-103. http://dx.doi.org/10.1016/j.hrmr.2008.10.001 
Elegbe, J.A. (2010). Talent management in the developing world: Adopting a global perspective. England: Gower Publishing Limited.

Grigoriadis, C., \& Bussin, M. (2007). Current practice with regard to short-term incentive schemes for middle managers. SA Journal of Human Resource Management, 5(1), 45-53.

Hertzberg, F., Mausner, B., \& Snyderman, B. (1957). The motivation to work. New York, NY: Wiley.

Highhouse, S., Lievens, F., \& Sinar, E.F. (2003). Measuring attraction to organisations. Educational and Psychological Measurement, 63(6), 986-1001. http://dx.doi.org/10.1177/0013164403258403

Holcombe-Ehrhart, K., \& Ziegert, J.C. (2005). Why are individuals attracted to organisations? Journal of Management, 31(6), 901-919. http://dx.doi. org/10.1177/0149206305279759

Holland, P., Sheehan, C., \& De Cieri, H. (2007). Attracting and retaining talent Exploring human resources development trends in Australia. Human Resource Development International, 10(3), 247-262. http://dx.doi. org/10.1080/13678860701515158

Jensen, D., McMullen, T., \& Stark, M. (2007). The manager's guide to rewards. New York, NY: Hay Group Inc.

Jurgensen, C.E. (1978). Job preferences: What makes a job good or bad? Journal of Applied Psychology, 63, 267-276. http://dx.doi.org/10.1037/0021-9010.63.3.267

Kearney, R. (2003). The determinants of state employee compensation Review of Public Personnel Administration, 23(4), 305-322. http://dx.doi org/10.1177/0734371X03259279

Lievens, F., Decaesteker, C., Coetsier, P., \& Geirnaert, J. (2001). Organizational attractiveness for prospective applicants: A person-organisation fit perspective. Applied Psychology: An International Review, 50(1), 30-51. http://dx.doi org/10.1111/1464-0597.00047

Miceli, M.P., \& Heneman, R.L. (2000). Contexual determinants of variable pay plan design: A proposed research framework. Human Resource Management Review 10(3), 289-305. http://dx.doi.org/10.1016/S1053-4822(00)00030-9

Mitchell, TR. \& Mickel, A.E. (1999). The meaning of money: An individual difference perspective. The Academy of Management Review, 24(3), 568-578.
Nieuwenhuizen, C. (2009). Scarcity, requirements and remuneration of applicants with management qualifications in the private-, public- and higher education sectors. Journal of Contemporary Management, 6, 310-324.

Pregnolato, M. (2010). Total rewards that retain: A study of demographic preferences. Master's dissertation, School of Management Studies, University of Cape Town Cape Town, South Africa. Retrieved February 2013, from http://hdl.handle.net/ $11180 / 2509$

Rousseau, D.M., \& Ho, V.T. (2000). Psychological contract issues in compensation. In S.L. Rynes, \& B. Gerhart (Eds.), Compensation in organizations (pp. 273-310). San Francisco, $\mathrm{CA}$ : Jossey-Bass Publishers.

Rumpel, S., \& Medcof, J.W. (2006). Total rewards: Good fit for tech workers. Research Technology Management, 49(5), 27-35.

Rynes, S.L. (1987). Compensation strategies for recruiting. Topics in tota compensation, 2, 185-196.

Simmons, J.P., Nelson, L.D., \& Simonsohn, U. (2011). False-positive psychology: Undisclosed flexibility in data collection and analysis allows presenting anythin as significant. Psychological Science, 1, 1-8.

Sutherland, M., \& Jordaan, W. (2004). Factors affecting the retention of knowledge workers. SA Journal of Human Resource Management, 2(2), 55-64. http://dx.doi. org/10.4102/sajhrm.v2i2.39

Tarique, I., \& Schuler, R. S. (2010). Global talent management: Literature review, integrative framework, and suggestions for further research. Journal of World Business, 45, 122-133. http://dx.doi.org/10.1016/j.jwb.2009.09.019

Tornikoski, C. (2011). Expatriate compensation: A total reward perspective. Doctoral dissertation, EMYLON Business School, Écully, France, \& University of Vaasa Vaasa, Finland. Retrieved February 2013, from http://hal.grenobleem.com/ docs/00/67/92/29/PDF/Tornikoski_29-06-2011_HAL.pdf

Van Rooy, D.J. (2010). Total rewards strategy for s multi-generational workforce. Master of Business Administration dissertation, Gordon Institute of Business from http://upetd.up.ac.za/thesis/available/etd-07232011-130927/

WorldatWork. (2007). Attraction and retention: The impact and prevalence of work life and benefit programs. Scottsdale, AZ: WorldatWork Press.

WorldatWork. (2011). Total rewards model. Retrieved February 2013, from http:// www.worldatwork.org/waw/adimLink?id=28330\&nonav $=y$ 